\title{
Analytical Methods for the Determination of Rosuvastatin in Pharmaceutical Formulations and Biological Fluids: A Critical Review
}

Marilene Lopes Ângelo, Fernanda de Lima Moreira, André Luís Morais Ruela, Ana Laura Araújo Santos, Hérida Regina Nunes Salgado \& Magali Benjamim de Araújo

To cite this article: Marilene Lopes Ângelo, Fernanda de Lima Moreira, André Luís Morais Ruela, Ana Laura Araújo Santos, Hérida Regina Nunes Salgado \& Magali Benjamim de Araújo (2018) Analytical Methods for the Determination of Rosuvastatin in Pharmaceutical Formulations and Biological Fluids: A Critical Review, Critical Reviews in Analytical Chemistry, 48:4, 317-329, DOI: 10.1080/10408347.2018.1439364

To link to this article: https://doi.org/10.1080/10408347.2018.1439364

曲 Published online: 13 Mar 2018.

Submit your article to this journal $\widetilde{T}$

Џ Article views: 127

Citing articles: 1 View citing articles $\square$ 


\title{
Analytical Methods for the Determination of Rosuvastatin in Pharmaceutical Formulations and Biological Fluids: A Critical Review
}

\author{
Marilene Lopes Ângelo ${ }^{a}$, Fernanda de Lima Moreira ${ }^{b}$, André Luís Morais Ruela $\mathbb{C D}^{c}$, Ana Laura Araújo Santos ${ }^{\mathrm{d}}$, \\ Hérida Regina Nunes Salgado (1D) ${ }^{\mathrm{e}}$, and Magali Benjamim de Araújo (iD) ${ }^{\mathrm{a}}$ \\ ${ }^{a}$ Faculty of Pharmaceutical Sciences, Federal University of Alfenas, Alfenas, Minas Gerais, Brazil; ${ }^{b}$ School of Pharmaceutical Sciences of Ribeirão Preto, \\ São Paulo University, Ribeirão Preto, São Paulo, Brazil; ' ${ }^{M}$ ultidisciplinary Health Institute, Federal University of Bahia, Vitória da Conquista, Bahia, Brazil; \\ ${ }^{\mathrm{d} S}$ School of Biological Sciences, Bangor University, Bangor, Wales, UK; ${ }^{e}$ Faculty of Pharmaceutical Sciences, UNESP, Araraquara, São Paulo, Brazil
}

\begin{abstract}
Rosuvastatin calcium (ROS), (Figure 1) belongs to the "statins" group, which is the 3-hydroxy-3methylglutaryl coenzyme A (HMG-CoA) reductase inhibitor. This drug is indicated for dyslipidemias treatment and can help to decrease the level of "bad cholesterol" and can consequently reduce the development of atherosclerosis and the risk of heart diseases. ROS was developed by Astra-Zeneca and it was approved in 2003 by the FDA in the United States. In 2015, under the trade name Crestor ${ }^{\circledR}$, it was the fourth largest selling drug in the United States with sales above $\$ 5$ billion. This study presents a literature review of analytical methods for the quantification of ROS in pharmaceutical preparations and biological fluids. The major analytical methods described in this study for ROS were spectrophotometry, highperformance liquid chromatography (HPLC) coupled to ultraviolet (UV) detection, and tandem mass spectrometry (LC-MS/MS).
\end{abstract}

\section{KEYWORDS}

Analytical methods; HPLC; LC-MS/MS; rosuvastatin; spectrophotometry

\section{Introduction}

Rosuvastatin calcium (ROS) is a member of a class of cholesterol-lowering medications commonly referred to as "statins," which was developed by Pharmaceutical Company AstraZeneca, and it was approved in the United States in 2003. ${ }^{[1]}$ Statins specifically inhibit the enzyme 3-hydroxy-3-methylglutaryl-coenzyme A (HMG-CoA) reductase, which converts HMG-CoA into mevalonic acid. HMG-CoA reductase is a rate-limiting step in the biosynthesis of cholesterol. ${ }^{[2]}$ Several statins, also called HMG-CoA reductase inhibitors, are commercially available in the market: Lipitor ${ }^{\circledR}$ (atorvastatin), Lescol $^{\circledR}$ (fluvastatin), Mevacor ${ }^{\circledR}$ (lovastatin), Livalo ${ }^{\circledR}$ (pitavastatin), Pravachol ${ }^{\circledR}$ (pravastatin), Crestor ${ }^{\circledR}$ (rosuvastatin), and Zocor $^{\circledR}$ (simvastatin). The statins are highly effective drugs in reductions in low-density lipoprotein cholesterol (LDL-C) levels. ${ }^{[3]}$ LDL-C is a primary atherogenic lipoprotein. Several clinical trials have shown the benefit of statin therapy in primary prevention of cardiovascular events due to the cholesterol reduction. ${ }^{[4-6]}$ Larger reductions in LDL-C levels are related with reductions in cardiovascular events, and within the statin class, ROS is responsible for the greatest reduction on LDL-C levels. ${ }^{[7,3]}$ Nowadays, there is an emerging interest in the application of statins in cancer treatment, since high levels of mevalonic acid production are observed in various types of malignancies, such as breast cancer, ${ }^{[8]}$ leukemia, ${ }^{[9]}$ lymphoma, ${ }^{[10]}$ and prostate carcinoma cells. ${ }^{[11-13]}$

The development of analytical methods for the quantification of statins in biological fluids is a key determinant in pharmacokinetics and drug-drug interactions studies. The clinical importance of the cytochrome P450 (CYP) enzymes and drug transporters has become apparent, mainly in the context of drug-drug interactions. ${ }^{[14]}$ The HMG-CoA reductase inhibitor, cerivastatin, was withdrawn from the market in August 2001 due the severe rhabdomyolysis produced during coadministration of gemfibrozil and cerivastatin. A metabolite of gemfibrozil inhibits CYP2C8-mediated metabolism of cerivastatin and greatly increases plasma concentrations of cerivastatin. ${ }^{[15]}$ The organic anion transporting polypeptide (OATP1B1) facilitates the hepatic uptake of most statins, mainly pravastatin and rosuvastatin. Interference with the function of this hepatic uptake transporter, as the co-administration with inhibitors (e.g., cyclosporine A) or genetic polymorphisms, could decrease the efficacy and safety of the statins. ${ }^{[16]}$ In this context, it is important to use well-characterized and fully validated analytical methods to yield reliable pharmacokinetic data. Several analytical methods have been developed for the quantitation of each HMG-CoA reductase inhibitor also in pharmaceutical formulations that are crucial during quality control process of pharmaceutical products. Furthermore, analytical methods for the quantification of mevalonate acid have been developed in order to be used as a biomarker for the enzyme inhibition by statins. ${ }^{[17-20]}$

Despite reviews about quantitation of statins in pharmaceutical formulations and biological samples have been previously published, none of these reviews focused on ROS analytical methods, perhaps because it is one of the latest statins 
introduced in the market. ${ }^{[21-23]}$ The aim of this review is to provide an overview of relevant published literature and a discussion of methods for the determination of ROS on its own or in mixtures, in pure form, formulations, and biological samples using different analytical procedures (HPLC-UV, LC-MS/MS, spectrophotometry, etc.).

\section{Rosuvastatin}

\section{Chemistry}

ROS is a synthetic compound produced as monocalcium bis (+)-7-(4-(4-fluorophenyl)-6-isopropyl-2-(N-methylN-methansulfonylaminopyrimidine)-5-yl)-(3R, 5S)-dihydroxy-(E)-6heptenoate. ${ }^{[2,25]}$ The configuration of ROS consists of a single enantiomer $(3 \mathrm{R}, 5 \mathrm{~S})$, formulated and administrated as a calcium salt of the active hydroxy acid. ${ }^{[26]}$ The chemical formula is $\mathrm{C}_{44} \mathrm{H}_{54} \mathrm{CaF}_{2} \mathrm{~N}_{6} \mathrm{O}_{12} \mathrm{~S}_{2}$ and molecular weight is $1001.141 \mathrm{~g} / \mathrm{mol}$ (Crestor $^{\circledR}$, U.S. approved label). ROS is a white amorphous powder that is sparingly soluble in water and methanol $(\mathrm{MeOH})$, and slightly soluble in ethanol $(\mathrm{EtOH}) .{ }^{[25,27]}$ The pharmacophore constitutes of a dihydroxy heptenoic acid portion, which binds to the active site of the target enzyme HMGCoA reductase. ${ }^{[2]}$ Differently from other statins, the addition of a stable polar methane sulfonamide group in the ROS structure confers relatively low lipophilicity. ${ }^{[28,29]}$ The $\log \mathrm{D}$ (distribution of the drug into octanol:water) measured at $\mathrm{pH} 7.4$ is -0.33 , which is comparable to pravastatin and lower than other statins (atorvastatin, fluvastatin, simvastatin, and cerivastatin). ${ }^{[2]}$ The commercial formulations of ROS tablets available contain 5, 10, 20 , or $40 \mathrm{mg}$ of ROS. ${ }^{[27]}$

\section{Pharmacodynamics, efficacy, and safety}

ROS produces beneficial effects on the lipid profile by inhibiting 3-hydroxy-3-methylglutaryl coenzyme A (HMG-CoA) reductase, a limiting enzyme in cholesterol biosynthesis that converts HMG-CoA to mevalonate. ROS is a competitive inhibitor of HMG-CoA reductase, presenting a chemical structure very similar to HMG portion of HMG-CoA. Olsson et al. ${ }^{[30]}$ have reported that a dosage of ROS from 1 to $80 \mathrm{mg}$ over 6 weeks has resulted in LDL-C reductions ranging from $34 \%$ to $65 \%$. Some clinical trials have demonstrated the effectiveness of ROS compared to other statins on the reduction of LDL-C. ${ }^{[31-33]}$ The STELLAR study showed the greatest efficacy of ROS in improving LDL-C, triglycerides, and HDL-C levels. It is considered the most effective statin in increasing HDL-C, ranging from $+7.7 \%$ to $+9.6 \%$ compared to $+2.1 \%$ to $+6.8 \%$ with other statins (atorvastatin, pravastatin, and simvastatin). ${ }^{[33]}$ In this same study, it was observed that ROS dosage of $10-80 \mathrm{mg}$ has reduced LDL-C $8.2 \%$ more than atorvastatin dosage of $10-80 \mathrm{mg}, 26 \%$ more than pravastatin dosage of $10-$ $40 \mathrm{mg}$, and $12-18 \%$ more than simvastatin dosage of $10-$ $80 \mathrm{mg} .{ }^{[33]}$ Most of the lipid therapies are aimed at achieving treatment goals from guideline bodies. ROS enabled a greater proportion of treated patients to National Cholesterol Education Program Adult Treatment Panel III (NCEP ATP III) and European LDL cholesterol goal. ${ }^{[33]}$ ROS can be associated with other drugs in order to improve the management of high-risk patients who cannot reach the cholesterol goal on maximal ROS dose monotherapy. A significant number of patients taking ROS/ezetimibe instead of ROS on its own achieved their NCEP ATP III cholesterol goal $(<100 \mathrm{mg} / \mathrm{dL}, 94.0 \%$ versus $79.1 \%$, respectively, $p<0.001)$. $^{[34]}$

The incidence of adverse events during ROS 10-40 mg daily therapy is comparable to those of other statins. ${ }^{[35]}$ In a clinical evaluation with 2579 patients taking ROS, myalgia was reported in $5.1 \%$ of patients and the creatine kinase elevation was reported in $2.1 \%$ of the patients. ${ }^{[36]}$ The myopathy (creatine kinase increasing 10-fold the upper limit of normal plus muscle symptoms) was $0.2 \%$ and all cases occurred in patients using high doses. ${ }^{[36]}$ A safety study detected the incidence of adverse effects per 10,000 patients taking ROS; the incidence of myopathy was 0.4 , of rhabdomyolysis was 0.4 , and of acute liver injury was 0.4 per 10,000 person-years. ${ }^{[37]}$ The dose range indicated in the U.S. label of ROS (Crestor ${ }^{\circledR}$, Astra Zeneca) is 5-40 mg daily, and $40 \mathrm{mg}$ is not indicated for initial therapy but is for patients that did not reach LDL-C goal with $20 \mathrm{mg} .{ }^{[27]}$

\section{Pharmacokinetics}

The oral bioavailability of ROS is approximately $20 \%$ and the peak plasma concentration $\left(C_{\max }\right)$ is reached 3-5 hours after administration of $10-80 \mathrm{mg}$ oral dose. $C_{\max }$ and area under the plasma concentration-time curve (AUC) increase proportionally to the dose. Administration of ROS with food decreased the rate of drug absorption by $20 \%$ as assessed by $C_{\text {max }}$; however, the extent of absorption is not affected when assessed by AUC. ${ }^{[27]}$ The mean volume of distribution at steady state of ROS is approximately $134 \mathrm{~L}$. ROS is $88 \%$ bound to plasma proteins, mainly albumin. ROS undergoes minimal metabolism with approximately $10 \%$ of radio-labeled dose recovered as metabolite. ${ }^{[27]}$ In vitro studies with cultured human hepatocytes showed an extremely slow metabolism with a single abundant metabolite, N-desmethyl ROS. Cytochrome 2C9 (CYP2C9) was the primary isoenzyme involved with minor contributions of CYP2C19 and CYP3A4. ${ }^{[38]}$ The evidence of the limited role of metabolism in the ROS clearance is supported by drug-interaction trials employing common CYP inhibitors. Co-administration of the CYP3A4 inhibitor ketoconazole did not produce meaningful changes in ROS exposure. ${ }^{[39]}$ Co-administration of a potent CYP2C9 inhibitor, fluconazole, produced only a slight increase in the systemic exposure of ROS. ${ }^{[40]}$ Recovery of ROS is primarily via fecal route of elimination with approximately $72 \%$ of absorbed ROS eliminated via bile secretion and $28 \%$ via renal excretion. The circulating plasma half-life is approximately 20 hours. ${ }^{[40]}$

No effects on the pharmacokinetics of ROS have been observed regarding age, sex, or time of day of administration (morning or evening). ${ }^{[41,42]}$ Nevertheless, metabolic ethnic differences play an important role in ROS disposition. The organic anion transporting polypeptide C (OATP1B1) is expressed in the basolateral membrane of hepatocytes and contributes to hepatic uptake of ROS. ${ }^{[43]}$ Several single-nucleotide polymorphisms (SNPs) in the gene encoding OATP1B1 (SLCO1B1) have already been described. Some of these SNPs, as OATP1B1 $521 \mathrm{C}$, show reduced function on the transporter. The frequency of OATP1B1 $521 \mathrm{C}$ has been reported as $11-16 \%$ in Japanese 
patients and $8-16 \%$ in other Asians backgrounds. ${ }^{[4,45]}$ It was observed an increase in plasma exposure of ROS in Asian population when compared with Caucasian patients $\left(\mathrm{AUC}_{0-t} 86 \%\right.$ and 55\% higher for ROS in Chinese and Japanese population, respectively). ${ }^{[4]}$ Due this issue, in the United States, the recommended initial dose of ROS for Asians is $5 \mathrm{mg}$, which is half of the dose recommended for Caucasians. ${ }^{[47]}$

\section{Analytical methods}

The development of analytical methods for the analysis of ROS in different matrices is very relevant, mainly to assist bioavailability, bioequivalence, and pharmacokinetic studies as well as monitoring the quality of the marketed product. HPLC coupled to UV or tandem mass spectrometry is the most used method for qualitative and quantitative analysis of ROS alone or in mixtures. UV-Visible Spectrophotometer was employed mainly in pure form and pharmaceutical formulations analysis. Other methods, such as capillary electrophoresis, fluorimetric methods (HPLC or spectrophotometry), thin-layer chromatography (TLC), and electrodes, were less used.

Spectrophotometric methods with UV-Visible detection have been developed for ROS analysis alone and in simultaneous determination as presented in Table $1 .^{[48-64]}$ The matrices most employed in the studies were standard and pharmaceutical formulations, except for the spectrofluorimetric method developed by Braga et al. ${ }^{[53]}$, which analyzed ROS in urine samples. The solvent most employed in spectrophotometric method was methanol $(\mathrm{MeOH})$. Derivative spectrophotometric determination of ROS was performed with the respective reagents and wavelength detection: safranin at $530 \mathrm{~nm}$, methylene blue at $655 \mathrm{~nm}$, iodine at 291 and $360 \mathrm{~nm}$, quinalizarin at $579 \mathrm{~nm}$, and bromocresol green at $416 \mathrm{~nm} .^{[50-52,54]}$ Spectrophotometric methods were developed for the estimation of ROS combined with fenofibrate in dosage formulations. ${ }^{[57,59,61,62]}$ Considering the analysis of ROS in combination or alone, the linearity was observed in concentrations from $0.48 \mu \mathrm{g} / \mathrm{mL}$ to $500 \mu \mathrm{g} / \mathrm{mL}$, nevertheless, in most cases, the typical range was around $1-10 \mu \mathrm{g} / \mathrm{mL}$.
There are plenty of analytical methods employing HPLC with UV detection for ROS determination in pharmaceutical formulations and biological fluids. Tables $2^{[25,56,65-77]}$ and $3^{[61,78-107]}$ show the reported HPLC methods developed for ROS analysis alone and in combination with other drugs, respectively. In general, HPLC-UV methods employed C18 analytical columns. The wavelength used in HPLC-UV methods ranged between 215 and $275 \mathrm{~nm}$, in general it was set to $242 \mathrm{~nm}$. The mobile phase commonly employed was $\mathrm{MeOH}$ and/or acetonitrile (ACN) as organic solvent and water or buffer with $\mathrm{pH}$ adjusted to 3.0. Since ROS is an acidic compound ( $\mathrm{pka}=4.6$ ), its retention time in the analytical column is likely to be $\mathrm{pH}$ dependent and lowering $\mathrm{pH}$ keeps $\mathrm{ROS}$ in its non-ionized form. The retention time observed in the main HPLC-UV methods revised was relatively short varying from 1.52 minutes to 6.7 minutes; however, some other methods presented longer retention times around 13 minutes. Extensive retention time of ROS was demonstrated in two methods developed by Kishore et al. ${ }^{[79]}$ (24.6 minutes) and Pasha et al. ${ }^{[92]}$ (33.5 minutes). More sensitive methods have been developed using HPLC-UV when compared with a UV-visible spectrophotometer. The most sensitive bioanalytical methods showed lower concentration on the linearity curve from $0.01 \mu \mathrm{g} / \mathrm{mL}$ to $0.03 \mu \mathrm{g} / \mathrm{mL}$, except for the method developed by Nasir et al. ${ }^{[96]}$ that was more sensitive with the value of $2 \mathrm{ng} / \mathrm{mL}$. However, other analytical and bioanalytical methods demonstrated higher sensitivity values ranging from $0.05 \mu \mathrm{g} / \mathrm{mL}$ to $30 \mu \mathrm{g} /$ $\mathrm{mL}$.

Table $4^{[56,108-125]}$ shows the LC-MS/MS methods developed for ROS analysis alone or in combination with other drugs determined in biological fluids. Most LC-MS/MS analyses were performed in positive ion mode $\left(\mathrm{ESI}^{+}\right)$for the quantification of ROS in human plasma. LC-MS/MS methods were performed with a $\mathrm{C} 18$ analytical column and the mobile phase was composed by $\mathrm{MeOH}$ or ACN as organic solvent and water with volatile additives including ammonium acetate and formic acid, which were added in order to enhance ionization and to get higher sensitivity of the method. The most employed method was multiple reaction monitoring (MRM) and the precursor

Table 1. Representative spectrophotometric methods for the analysis of ROS alone or in combined dosage formulations.

\begin{tabular}{|c|c|c|c|c|c|}
\hline Analyte(s) & Matrices & Wavelength (nm) & Solvent or reagent & Linear range for ROS & Reference \\
\hline ROS & Tablet & 243 & $\mathrm{MeOH}$ & $1-60 \mu \mathrm{g} / \mathrm{mL}$ & {$[48]$} \\
\hline ROS & Standard and tablet & 244 & $\mathrm{MeOH}$ & $2-18 \mu \mathrm{g} / \mathrm{mL}$ & [49] \\
\hline \multirow[t]{2}{*}{ ROS } & Standard and tablet & $530(A)$ or $655(B)$ & $\begin{array}{l}\text { Safranin } 0 \text { in water }(A) \text {; methylene } \\
\quad \text { blue in alkaline buffer of } \mathrm{pH} 9.8(\mathrm{~B})\end{array}$ & A: $6.0-23.0 \mu \mathrm{g} / \mathrm{mL}$ & {$[50]$} \\
\hline & & & & B: $3.5-10.5 \mu \mathrm{g} / \mathrm{mL}$ & \\
\hline ROS & Standard and tablets & $291 ; 360$ & lodine/ACN & $2.408-48.154 \mu \mathrm{g} / \mathrm{mL}$ & {$[51]$} \\
\hline ROS & Tablets & 579 & MeOH/Quinalizarin & $6-15 \mathrm{mg} / \mathrm{L}$ & {$[52]$} \\
\hline ROS & Urine & $\lambda_{(\mathrm{exc})}=227 ; \lambda_{(\mathrm{em})}=370$ & Acidic medium $\mathrm{pH} 2$ & $0.38-5 \mathrm{mg} / \mathrm{L}$ & [53] \\
\hline ROS & Standard and tablets & 416 & Chloroform/Bromocresol green & $0.482-24.077 \mu \mathrm{g} / \mathrm{mL}$ & [54] \\
\hline ROS & Tablets & 518 & Chloroform/Safranin & $5-25 \mu \mathrm{g} / \mathrm{mL}$ & {$[55]$} \\
\hline ROS & Capsules and tablets & 242 & $\mathrm{MeOH}$ & $4-16 \mu \mathrm{g} / \mathrm{mL}$ & [56] \\
\hline ROS; FEN & Bulk and tablets & 244 ROS; 286.7 FEN & $\mathrm{MeOH}$ & $1-10 \mu \mathrm{g} / \mathrm{mL}$ & {$[57]$} \\
\hline ROS; EZE; PIT & Tablets & $\lambda_{(\mathrm{exc})}=315 ; \lambda_{(\mathrm{em})}=362$ & $\mathrm{MeOH}$ & $0.5-10 \mu \mathrm{g} / \mathrm{mL}$ & [58] \\
\hline ROS; FEN & Tablet & 243 ROS; 224 FEN & $\mathrm{MeOH}$ & $4-12 \mu \mathrm{g} / \mathrm{mL}$ & [59] \\
\hline ROS; ASP & Capsule & 259 ROS; 238 ASP & MeOH:water (1:1) & $0.5-2 \mu \mathrm{g} / \mathrm{mL}$ & {$[60]$} \\
\hline ROS; FEN & Tablet & 243 ROS; 287 FEN & $\mathrm{MeOH}$ & $1-7 \mu \mathrm{g} / \mathrm{mL}$ & [61] \\
\hline ROS; FEN & Tablet & 244 ROS; 286.7 FEN & $\mathrm{MeOH}$ & $1-10 \mu \mathrm{g} / \mathrm{mL}$ & {$[62]$} \\
\hline ROS; GLI & Tablet & 241 ROS; 231 GLI & $0.1 \mathrm{M} \mathrm{NaOH}$ & $10-22 \mu \mathrm{g} / \mathrm{mL}$ & {$[63]$} \\
\hline ROS; FEN & Tablet & 224 FEN; 243258 ROS & $\mathrm{MeOH}$ & $4-12 \mu \mathrm{g} / \mathrm{mL}$ & {$[64]$} \\
\hline
\end{tabular}




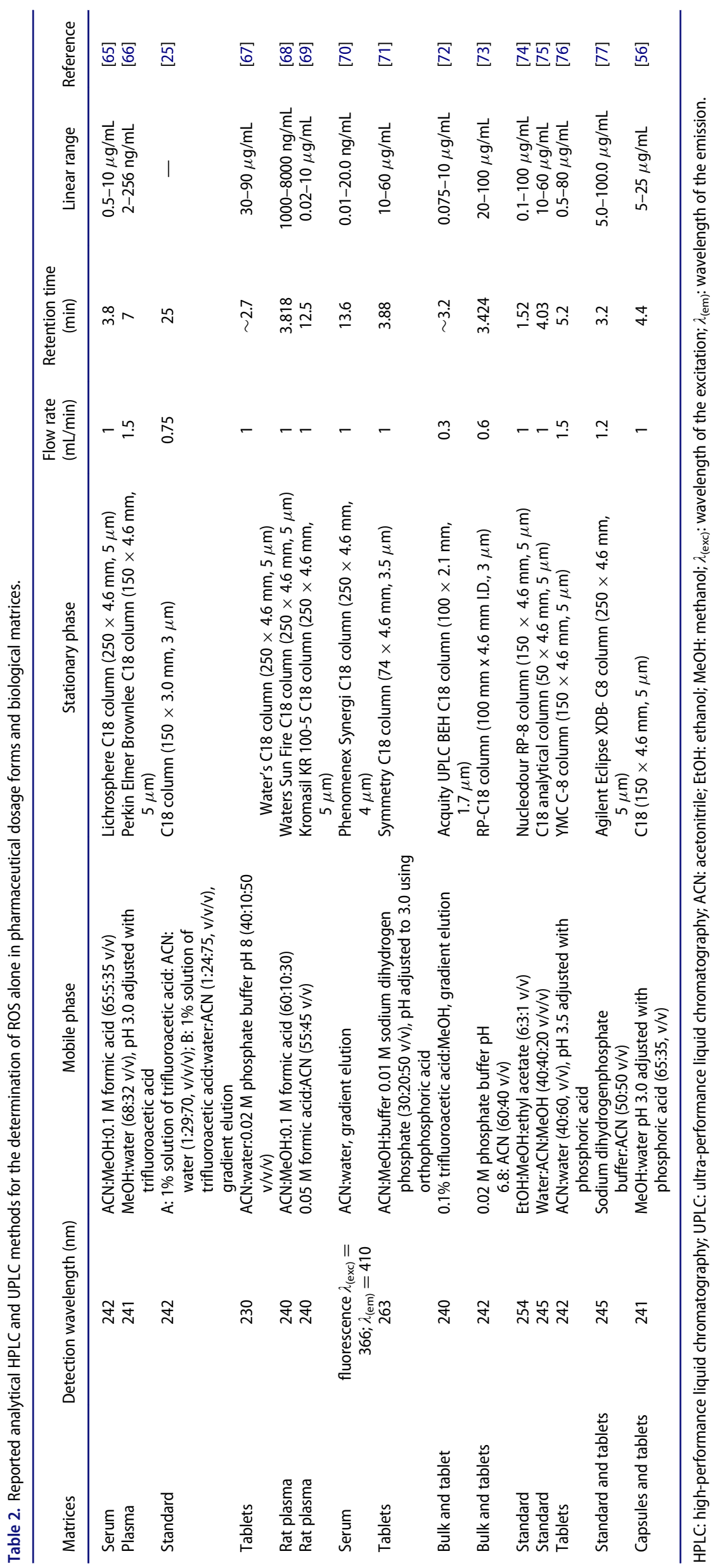




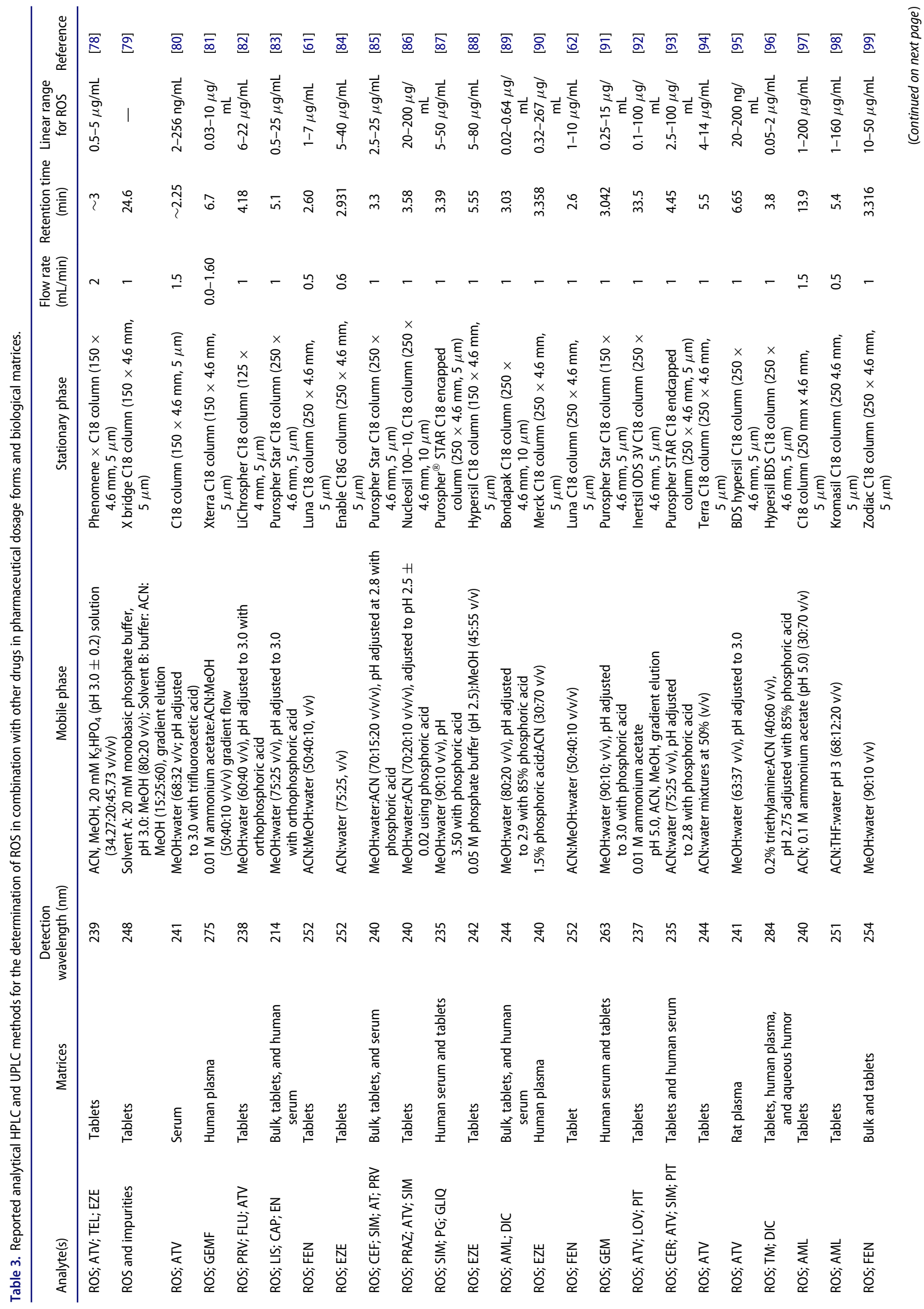




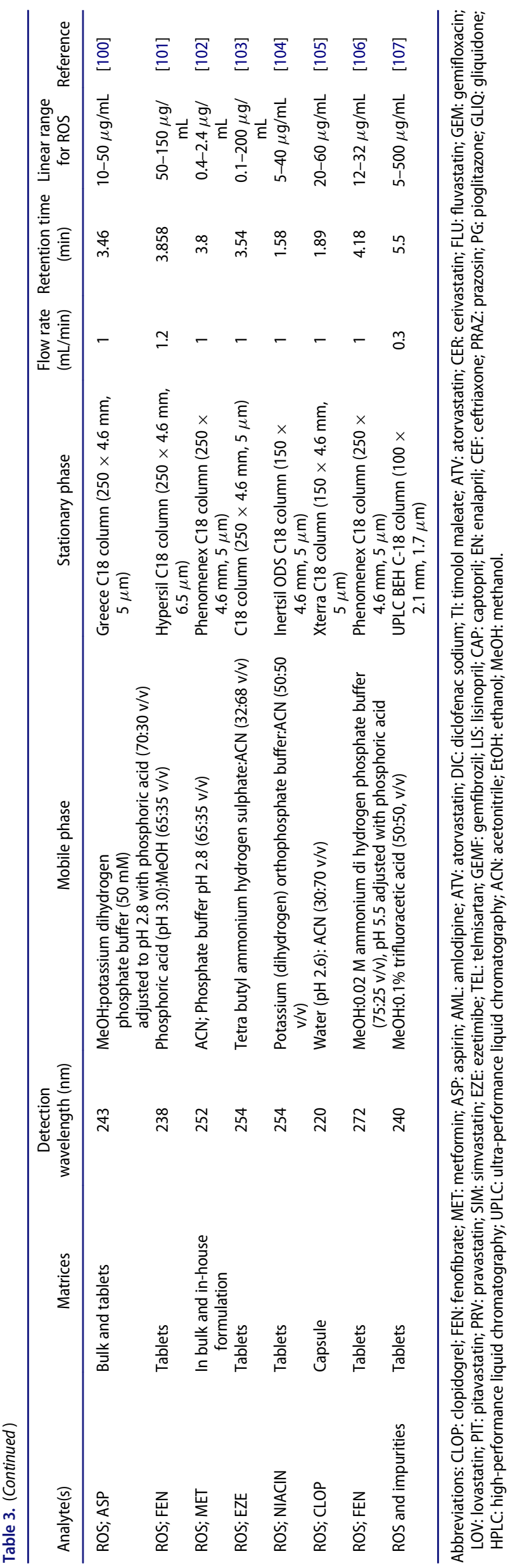




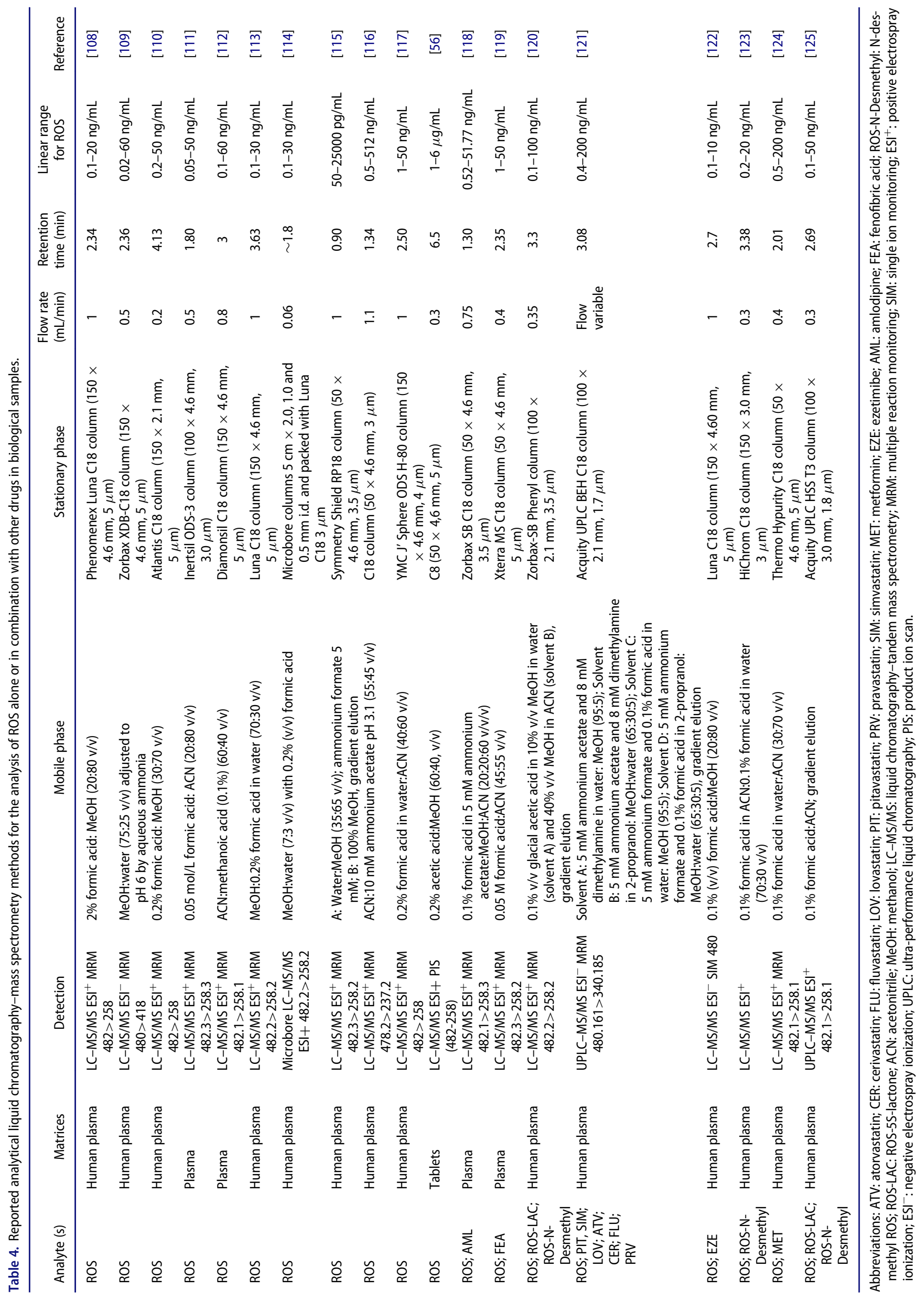


Table 5. Representative methods.

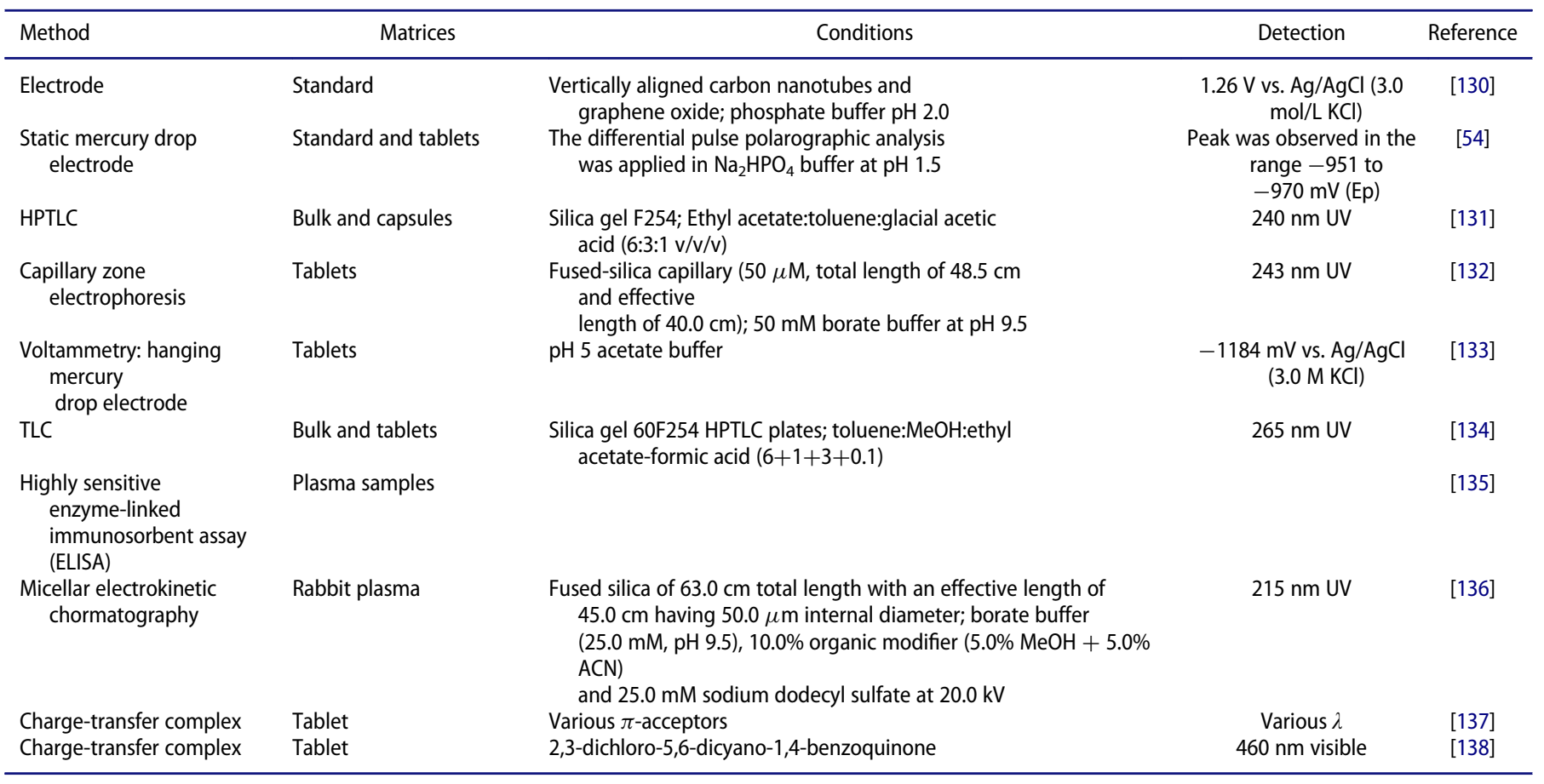

Abbreviations: HPTLC: high-performance thin-layer chromatography; TLC: thin-layer chromatography; UV: ultraviolet.

ion selected was $\left[\mathrm{M}+\mathrm{H}^{+}\right]$at $m / z$ 482. ROS can be detected in both positive and negative ionization modes of a mass spectrometer, since its structure contains a pyrimidine ring and a carboxylic ring. In order to improve sensitivity, electrospray ionization in the negative mode $\left(\mathrm{ESI}^{-}\right)$could be used for MS/ MS detection of ROS in plasma that produced abundant deprotonated molecule $\left[\mathrm{M}-\mathrm{H}^{-}\right]$at $m / z 480$ as demonstrated by Gao et al. ${ }^{[109]}$ Retention times were very short, including methods for simultaneous analysis with other drugs, ranging from 0.9 minutes up to 4.1 minutes. Isocratic elution was applied in most cases. More sensitive methods have been developed using LC-MS/MS when compared with HPLC-UV with linearity ranging from $0.02 \mathrm{ng} / \mathrm{mL}$ to $512 \mathrm{ng} / \mathrm{mL}$. UPLC is a separation category that uses sub-2- $\mu \mathrm{m}$ porous particles and decreases analysis time and solvent consumption when compared with the conventional LC methods ${ }^{[125-128]}$ Despite the advantages, there were a few UPLC methods developed to estimate ROS in pharmaceutical forms ${ }^{[72,107]}$ and biological samples. ${ }^{[125]}$

It is useful for the development of analytical methods for simultaneous determination of ROS and other drugs used during the treatment of hyperlipidemic patients. For instance, ezetimibe is a drug used in association with ROS due the greater LDL-C reduction compared with ROS alone. ${ }^{[34]} \mathrm{A}$ method using LC-MS/MS equipped with an ESI interface and operated in negative ionization mode was employed with this aim contrast to the most usual method that uses positive ionization mode for ROS detection. ${ }^{[122]}$ Other simultaneous analyses with lipid-lowering drugs were performed with fenofibric acid in human plasma using LC-MS/MS ${ }^{[119]}$ and in bulk and tablets using HPLC detection. ${ }^{[61]}$ Gemfibrozil was analyzed simultaneously with ROS in human plasma samples employing the HPLC-UV method. ${ }^{[81]}$ Sharma et al. ${ }^{[62]}$ and Ashfaq et al. ${ }^{[90]}$ have proposed HPLC methods for the quantification of ROS with fenofibrate in tablets and ezetimibe in human plasma, respectively. Spectrophotometric methods were developed for simultaneous determination of ROS and fenofibrate in tablets, ${ }^{[57,59,61,62]}$ since these drugs are associated in the same dosage form, for example, tablets with $10 \mathrm{mg}$ of ROS and $80 \mathrm{mg}$ of fenofibrate. ROS is commonly associated with antihypertensive drugs, since high-serum cholesterol has been frequently reported in patients with arterial hypertension. In this context, a simultaneous method for ROS and lisinopril, captopril, and enalapril analysis in pharmaceutical dosage and human serum was developed using HPLC. ${ }^{[83]}$ Simultaneous determination of amlodipine and ROS in human plasma was performed using LC-MS/MS with a linear range of $0.52-51.77 \mathrm{ng} / \mathrm{mL}$ for ROS. ${ }^{[118]}$

There are a few works that describe the determination of a number of statin structures simultaneously, probably because statins are not used with other statins concurrently during the treatment of hyperlipidemic patients. A method was developed for simultaneous determination of atorvastatin, lovastatin, pravastatin, ROS, and simvastatin in pharmaceutical formulations and in vitro metabolism samples using HPLC. ${ }^{[92]}$ The method employed a C18 column and mobile phase comprising $0.01 \mathrm{M}$ ammonium acetate $(\mathrm{pH} 5.0), \mathrm{ACN}$, and $\mathrm{MeOH}$. The chromatography run was delayed with the last analyte (ROS) eluting at 35.5 minutes. ${ }^{[79]}$ Gomes et al. ${ }^{[82]}$ proposed a short chromatographic run of simultaneous estimation of fluvastatin, atorvastatin, pitavastatin, and ROS in tablets using the HPLC method. The retention time for ROS was 4.18 minutes and the last analyte eluted at 4.95 minutes. Recently, Kosek et al. ${ }^{[121]}$ reported a sensitive LC-MS/MS method for simultaneous quantitation of all statins in human plasma. The mass spectrometry was conducted in negative ion electrospray mode for ROS determination and it showed retention time at 3.08 minutes and the lower concentration in the linearity range of $4 \mathrm{ng} / \mathrm{mL}$. 


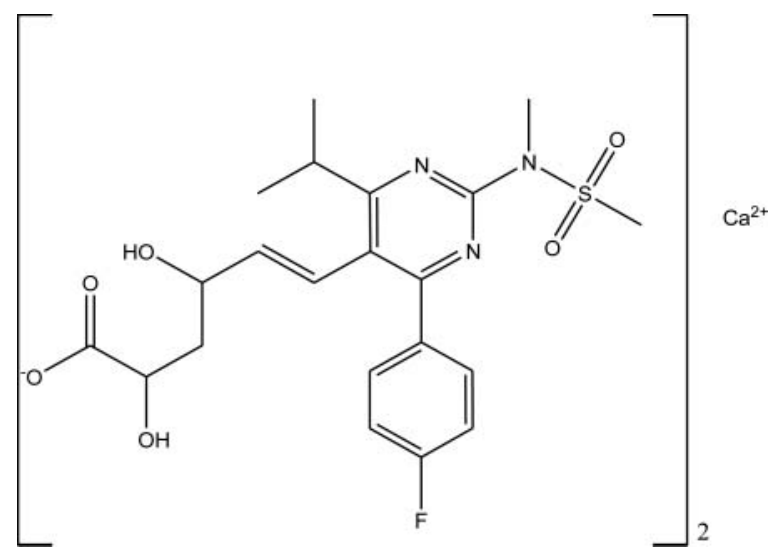

Figure 1. Chemical structure of rosuvastatin calcium.

The ROS hepatic metabolism is negligible with low concentration of $\mathrm{N}$-desmethyl metabolite ( $<10 \%$ of parent drug) and 5 S-lactone (12-24\% of parent drug) product formed in hepatocytes. ${ }^{[129]}$ Macwan et al. ${ }^{[120]}$ developed and validated a sensitive method using LC-MS/MS in order to determine ROS and its metabolites in human plasma.

Other techniques for ROS quantification were also applied, including capillary zone electrophoresis, mercury drop electrode, highly sensitive enzyme-linked immunosorbent assay (ELISA), high-performance thin-layer chromatography (HPTLC), and TLC, as demonstrated in Table 5. ${ }^{[54,130-138]} \mathrm{A}$ microwell-based automated spectrophotometric method for determination of drugs using a colored charge-transfer (CT) complex has been developed as an alternative for the conventional spectrophotometric technique. ${ }^{[137-140]}$ This non-conventional spectrophotometric assay demonstrated advantages, such as automation, lower consumption of organic solvents, and relative sensitivity with the limit of quantification of $7.85 \mu \mathrm{g} /$ well for the quantification of ROS. ${ }^{[138]}$ Immunoassays have been widely used in pharmaceutical and clinical analysis of drugs. ${ }^{[141-144]}$ In this context, ROS analysis performed employing ELISA demonstrated high specificity and sensitivity with limit of detection at $40 \mathrm{pg} / \mathrm{mL} .{ }^{[135]}$ Other recent technique is the use of carbon nanotubes for the electroanalysis of drugs. A composite of vertically aligned carbon nanotubes and graphene oxide was used as the electrode material for the quantification of ROS in pharmaceutical and biological samples. ${ }^{[130]}$

\section{Conclusions}

In this review, we have discussed the present state-of-the-art of spectrophotometric and chromatographic methods for the quantification of ROS in biological matrices and pharmaceutical formulations. Considering that ROS is a new statin approved in 2003, a considerable number of methods for its quantification are available. Spectrophotometric methods with UV-visible detection are particularly applied in ROS quantification in pharmaceutical formulations. Nevertheless, it is evident that HPLC-UV is the technique of choice for the quantification of ROS in biological matrices and pharmaceutical formulations. Further, LC-MS/MS methods is overcoming the HPLC-UV methods for the analysis of the ROS in biological fluids. The particular advantages of LC-MS/MS methods when compared with other techniques are selectivity and sensitivity with the quantification of ROS in the $\mathrm{ng} / \mathrm{mL}$ range.

\section{Conflict of interest}

The authors declare no conflicts of interest.

\section{Funding}

The authors acknowledge CAPES and CNPq (Process: 441888/2015-1) for financial support. FLM is grateful to FAPESP (Grant number: 2016/239382) for financial support.

\section{ORCID}

André Luís Morais Ruela (iD http://orcid.org/0000-0003-1258-8705

Hérida Regina Nunes Salgado (iD http://orcid.org/0000-0002-0385-340X

Magali Benjamim de Araújo iD http://orcid.org/0000-0002-3564-4338

\section{References}

[1] U.S. Food and Drug Administration. Crestor (ROS Calcium) Tablets Drug Approval Package. https://www.accessdata.fda.gov/drug satfda_docs/nda/2003/21-366_Crestor.cfm (accessed Aug 12, 2017).

[2] Istvan, E. S.; Deisenhofer, J. Structural Mechanism for Statin Inhibition of HMG-CoA Reductase. Science 2001, 292, 1160-1164.

[3] Law, M. R.; Wald, N. J.; Rudnicka, A. R. Quantifying Effect of Statins on Low Density Lipoprotein Cholesterol, Ischaemic Heart Disease, and Stroke: Systematic Review and Meta-Analysis. Brit. Med. J. 2003, 326, 1423 .

[4] The ALLHAT Officers and Coordinators for the ALLHAT Collaborative Research Group. Major Outcomes in Moderately Hypercholesterolemic, Hypertensive Patients Randomized to Pravastatin vs. Usual Care: The Antihypertensive and Lipid-Lowering Treatment to Prevent Heart Attack Trial (ALLHAT-LLT). JAMA 2002, 288, 2998-3007.

[5] Sever, P. S.; Dahlof, B.; Poulter, N. R.; Wedel, H.; Beevers, G.; Caulfield, M.; Collins, R.; Kjeldsen, S. E.; Kristinsson, A.; McInnes, G. T.; et al. Prevention of Coronary and Stroke Events with Atorvastatin in Hypertensive Patients Who Have Average or Lower-Than-Average Cholesterol Concentrations, in the Anglo-Scandinavian Cardiac Outcomes Trial-Lipid Lowering Arm (ASCOT-LLA): A Multicenter Randomized Controlled Trial. Lancet 2003, 361, 1149-1158.

[6] Scandinavian Simvastatin Survival Study Group. Randomized Trial of Cholesterol Lowering in 4444 Patients with Coronary Heart Disease: The Scandinavian Simvastatin Survival Study (4S). Lancet 1994, 344, 1383-1389.

[7] White, C. M. A. Review of the Pharmacologic and Pharmacokinetic Aspects of Rosuvastatin. J. Clin. Pharmacol. 2002, 42, 963-970.

[8] Dalenc, F.; Giamarchi, C.; Petit, M.; Poirot, M.; Favre, G.; Faye, J.-C. Farnesyl-Transferase Inhibitor R115, 577 Enhances Tamoxifen Inhibition of MCF-7 Cell Growth through Estrogen Receptor Dependent and Independent Pathways. Breast Cancer Res. 2005, 7, R1156-R1167.

[9] Qi, X.-F.; Zheng, L.; Lee, K. J.; Kim, C. S.; Cai, D. Q.; Wu, Z.; Qin, J. W.; Yu, Y. H.; Kim, S. K. HMG-CoA Reductase Inhibitors Induce Apoptosis of Lymphoma Cells by Promoting ROS Generation and Regulating Akt, Erk and p38 Signals Via Suppression of Mevalonate Pathway. Cell Death Dis. 2013, 4, e518.

[10] Van-de-Donk, N. W.; Bloem, A. C.; van-de-Spek, E.; Lokhorst, H. M. New Treatment Strategies for Multiple Myeloma by Targeting BCL-2 and the Mevalonate Pathway. Curr. Pharm. Des. 2006, 12, 327-340.

[11] Roy, M.; Kung, H.-J.; Ghosh, P. M. Statins and Prostate Cancer: Role of Cholesterol Inhibition Vs. Prevention of Small GTP-Binding Proteins. Am. J. Cancer Res. 2011, 1, 542-561. 
[12] Gruenbacher, G.; Thurnher, M. Mevalonate Metabolism in Cancer. Cancer Lett. 2015, 356, 192-196.

[13] Safwat, S.; Ishak, R. A.; Hathout, R. M.; Mortada, N. D. Statins Anticancer Targeted Delivery Systems: Re-Purposing and Old Molecule. J. Pharm. Pharmacol. 2017, 69, 613-624.

[14] Huang, S-.M.; Strong, J. M.; Zhang, L.; Reynolds, K. S.; Nallani, S.; Temple, R.; Abraham, S.; Habet, S. A.; Baweja, R. K.; Burckart, G. J.; et al. New Era in Drug Interaction Evaluation: US Food and Drug Administration Update on CYP Enzymes, Transporters, and the Guidance Process. J. Clin. Pharmacol. 2008, 48, 662-670.

[15] Backman, J. T.; Kyrklund, C.; Neuvonen, M.; Neuvonen, P. J. Gemfibrozil Greatly Increases Plasma Concentrations of Cerivastatin. Clin. Pharmacol. Ther. 2002, 72, 685-691.

[16] Neuvonen, P. J.; Niemi, M.; Backman, J. T. Drug Interactions with Lipid-Lowering Drugs: Mechanisms and Clinical Relevance. Clin. Pharmacol. Ther. 2006, 80, 565-581.

[17] Jemal, M.; Schuster, A.; Whigan, D. B. Liquid Chromatography/Tandem Mass Spectrometry Methods for Quantitation of Mevalonic Acid in Human Plasma and Urine: Method Validation, Demonstration of Using a Surrogate Analyte, and Demonstration of Unacceptable Matrix Effect in Spite of Use of a Stable Isotope Analog Internal Standard. Rapid Commun. Mass Spectrom. 2003, 17, 1723-1734.

[18] Wani, T. A.; Samad, A.; Tandon, M.; Saini, G. S.; Sharma, P. L.; Pillai, K. K. The Effects of Rosuvastatin on the Serum Cortisol, Serum Lipid, and Serum Mevalonic Acid Levels in the Healthy Indian Male Population. AAPS PharmSciTech 2010, 11, 425-432.

[19] Saini, G. S.; Wani, T. A.; Gautam, A.; Varshney, B.; Ahmed, T.; Rajan, K. S.; Pillai, K. K.; Paliwal, J. K. Validation of the LC-MS/MS Method for the Quantification of Mevalonic Acid in Human Plasma and Determination of the Matrix Effect. J. Lipid Res. 2006, 47, 2340-2345.

[20] Saini, G. S.; Wani, T. A.; Ahmed, T.; Parvez, N.; Paliwal, J. K.; Pillai, K. K. Effect of Food and Rosuvastatin on Plasma Mevalonic Acid Levels in Male Rats. Ethiop. Pharm. J. 2006, 24, 59-64.

[21] Patel, M.; Kothari, C. Critical Review of Statins: A Bio-Analytical Perspective for Therapeutic Drug Monitoring. Trends Anal. Chem. 2017, 86, 206-221.

[22] Kokilambigai, K. S.; Seetharaman, R.; Lakshmi, K. S. Critical Review on the Analytical Techniques for the Determination of the Oldest Statin Atorvastatin in Bulk, Pharmaceutical Formulations and Biological Fluids. Crit. Rev. Anal. Chem. 2017, 46, 1-18.

[23] Nirogi, R.; Mudigonda, K.; Kandikere, V. Chromatography-Mass Spectrometry Methods for the Quantitation of Statins in Biological Samples. J. Pharm. Biomed. Anal. 2007, 44, 379-387.

[24] Watanabe, M.; Koike, H.; Ishiba, T.; Okada, T.; Seo, S.; Hirai, K. Synthesis and Biological Activity of Methanesulfonamide Pyrimidine and N-methanesulfonyl pvrrole-Substituted 3,5-Dihydroxy-6 Heptenoates, a Novel Series of HMG-CoA Reductase Inhibitors. Bioorg. Med. Chem. 1997, 5, 437-444.

[25] EP. European Pharmacopoeia, 8th edition, Supplement 8.4; EP: Strasbourg, 2015, 4807-4809.

[26] Chapman, M. J.; McTaggartb, F. Optimizing the Pharmacology of Statins: Characteristics of Rosuvastatin. Atheroscler. Suppl. 2002, 2, 33-37.

[27] Drugs@FDA page. Crestor (ROS Calcium, MSD), Astra-Zeneca. https://www.accessdata.fda.gov/drugsatfda_docs/label/2012/ 021366 Orig1s024Lbl-TrackedchangesLBL.pdf (accessed Aug 12, 2017).

[28] Buckett, L.; Ballard, P.; Davidson, R.; Dunkley, C.; Martin, L.; Stafford, J.; McTaggart, F. Selectivity of ZD4522 for Inhibition of Cholesterol Synthesis in Hepatic Versus Non-Hepatic Cells. Atherosclerosis 2000, 151, 41, Abstract MoP29:W6.

[29] Smith, G.; Davidson, R.; Bloor, S.; Burns, K.; Calnan, C.; McAulay, P.; Torr, N.; Ward, W.; McTaggart, F. Pharmacological Properties of ZD4522-A New HMG-CoA Reductase Inhibitor. Atherosclerosis 2000, 151, 39, Abstract MoP20:W6.

[30] Olsson, A. G.; Pears, J.; McKeller, J.; Mizan, J.; Raza, A. Effect of Rosuvastatin on Low-Density Lipoprotein Cholesterol in Patients with Hypercholesterolemia. Am. J. Cardiol. 2001, 88, 504-508.
[31] Brown, W. V.; Bays, H. E.; Hassman, D. R.; McKenney, J.; Chitra, R.; Hutchinson, H.; Miller, E. Efficacy and Safety of Rosuvastatin Compared with Pravastatin and Simvastatin in Patients with Hypercholesterolemia: A Randomized, Double-Blind, 52-Week Trial. Am. Heart J. 2002, 144, 1036-1043.

[32] Blasetto, J. W.; Stein, E. A.; Brown, W. V.; Chitra, R.; Raza, A. Efficacy of Rosuvastatin Compared with Other Statins at Selected Starting Doses in Hypercholesterolemic Patients and in Special Population Groups. Am. J. Cardiol. 2003, 91, 3C-10C.

[33] Jones, P. H.; Davidson, M. H.; Stein, E. A.; Bays, H. E.; McKenney, J. M.; Miller, E.; Cain, V. A.; Blasetto, J. W. (STELLAR study group). Comparison of the Efficacy and Safety of Rosuvastatin versus Atorvastatin, Simvastatin, and Pravastatin across Doses (STELLAR* Trial). Am. J. Cardiol. 2003, 92, 152-160.

[34] Ballantyne, C. M.; Weiss, R.; Moccetti, T.; Vogt, A.; Eber, B.; Sosef, F.; Duffield, E. Efficacy and Safety of Rosuvastatin $40 \mathrm{mg}$ Alone or in Combination with Ezetimibe in Patients at High Risk of Cardiovascular Disease (Results from the EXPLORER Study). Am. J. Cardiol. 2007, 99, 673-680.

[35] Shepherd, J.; Kastelein, J. J. P.; Bittner, V.; Deedwania, P.; Breazna, A.; Dobson, S.; Wilson, D. J.; Zuckerman, A.; Wenger, N. K. Effect of Intensive Lipid Lowering with Atorvastatin on Renal Function in Patients with Coronary Heart Disease: The Treating to New Targets (TNT) Study. Clin. J. Am. Soc. Nephrol. 2007, 2, 1131-1139.

[36] Olsson, A. G.; McTaggart, F.; Raza, A. Rosuvastatin: A Highly Effective New HMG-CoA Reductase Inhibitor. Cardiovasc. Drug Rev. 2002, 20, 303-328.

[37] García-Rodríguez, L. A.; Massó-González, E. L.; Wallander, M. A.; Johansson, S. The Safety of Rosuvastatin in Comparison with Other Statins in Over 100000 Statin Users in UK Primary Care. Pharmacoepidemiol. Drug Saf. 2008, 17, 943-952.

[38] McCormick, A. D.; McKillop, D.; Butters, C. J.; Miles, G. S.; Baker, T.; Touchi, A. ZD4522-An HMG-CoA Reductase Inhibitor Free of Metabolically Mediated Drug Interactions: Metabolic Studies in Human in Vitro Systems. J. Clin. Pharmacol. 2000, 40, 1055, Abstract 46.

[39] Cooper, K. J.; Martin, P. D.; Dane, A. L.; Warwick, M. J.; Raza, A.; Schneck, D. W. Lack of Effect of Ketoconazole on the Pharmacokinetics of Rosuvastatin in Healthy Subjects. Br. J. Clin. Pharmacol. 2003, 55, 94-99.

[40] Cooper, K. J.; Martin, P. D.; Dane, A. L.; Warwick, M.; Schneck, D.; Cantarini, M. The Effect of Fluconazole on the Pharmacokinetics of Rosuvastatin. Eur. J. Clin. Pharmacol. 2002, 58, 527-531.

[41] Martin, P. D.; Dane, A. L.; Nwose, O. M.; Schneck, D. W.; Warwick, M. J. No Effect of Age or Gender on the Pharmacokinetics of Rosuvastatin: A New HMG-CoA Reductase Inhibitor. J. Clin. Pharmacol. 2002, 42, 1116-1121.

[42] Martin, P. D.; Mitchell, P. D.; Schneck, D. W. Pharmacodynamic Effects and Pharmacokinetics of a New HMG-CoA Reductase Inhibitor, Rosuvastatin, after Morning or Evening Administration in Healthy Volunteers. Br. J. Clin. Pharmacol. 2002, 54, 472-477.

[43] Kitamura, S.; Maeda, K.; Wang, Y.; Sugiyama, Y. Involvement of Multiple Transporters in the Hepatobiliary Transport of Rosuvastatin. Drug Metab. Disp. 2008, 36, 2014-2023.

[44] Niemi, M.; Pasanen, M. K.; Neuvonen, P. J. Organic Anion Transporting Polypeptide 1B1: A Genetically Polymorphic Transporter of Major Importance for Hepatic Drug Uptake. Pharmacol. Rev. 2011, 63, 157-181.

[45] Nozawa, T.; Nakajima, M.; Tamai, I.; Noda, K.; Nezu, J.-I.; Sai, Y.; Tsuji, A.; Yokoi, T. Genetic Polymorphisms of Human Organic Anion Transporters OATP-C (SLC21A6) and OATP-B (SLC21A9): Allele Frequencies in the Japanese Population and Functional Analysis. J. Pharmacol. Exp. Ther. 2002, 302, 804-813.

[46] Birmingham, B. K.; Bujac, S. R.; Elsby, R.; Azumaya, C. T.; Wei, C.; Chen, Y.; Mosqueda-Garcia, R.; Ambrose, H. L. Impact of ABCG2 and SLCO1B1 Polymorphisms on Pharmacokinetics of Rosuvastatin, Atorvastatin and Simvastatin Acid in Caucasian and Asian Subjects: A Class Effect? Eur. J. Clin. Pharmacol. 2015, 71, 341-355. 
[47] U.S. Food and Drug Administration. FDA Public Health Advisory for Crestor (ROS), 2005. https://www.fda.gov/Drugs/DrugSafety/ PostmarketDrugSafetyInformationforPatientsandProviders/ ucm051756.htm (accessed Aug 12, 2017).

[48] Uyar, B.; Celebier, M.; Altinoz, S. Spectrophotometric Determination of Rosuvastatin Calcium in Tablets. Pharmazie 2007, 62, 411-413.

[49] Gupta, A.; Mishra, P.; K. Shah, K. Simple UV Spectrophotometric Determination of Rosuvastatin Calcium in Pure Form and in Pharmaceutical Formulations. E-J. Chem. 2009, 6, 89-92.

[50] Krishna, M. V.; Sankar, D. G. Extractive Spectrophotometric Methods for the Determination of Rosuvastatin Calcium in Pure Form and in Pharmaceutical Formulations by Using Safranin O and Methylene Blue. E-J. Chem. 2007, 4, 46-49.

[51] Ramadan, A. A.; Mandil, A.; Alshelhawi, N. Spectrophotometric Determination of Rosuvastatin Calcium in Pure Form and Pharmaceutical Formulations by the Oxidation Using Iodine and Formation Triiodide Complex in Acetonitrile. Int. J. Pharm. Pharm. Sci. 2014, 6 (5), 579-585.

[52] Lima, M. F.; Cassella, R. J.; Pacheco, W. F. Spectrophotometric Determination of Rosuvastatin in Pharmaceutical Formulations Using Quinalizarin. Braz. J. Pharm. Sci. 2017, 53 (3), 1-8.

[53] Braga, V. S. M.; Mancilha, T. P.; Cassella, R. J.; Pacheco, W. F. Determination of Rosuvastatin in Urine by Spectrofluorimetry After Liquid-Liquid Extraction and Derivatization in Acidic Medium. J. Fluoresc. 2013, 23, 49-55.

[54] Ramadan, A. A; Mandil, H.; Alsayed-Ali, R. Spectrophotometric Determination of Rosuvastatin in Pure Form and Pharmaceutical Formulations Through Ion-Pair Complex Formation Using Bromocresol Green. Int. J. Pharm. Pharm. Sci. 2015, 7 (11), 191-198.

[55] Prajapati P. B.; Bodiwala K. B.; Marolia B. P.; Rathod I. S.; Shah S. A. Development and Validation of Extractive Spectrophotometric Method for Determination of Rosuvastatin Calcium in Pharmaceutical Dosage Forms. J. Pharm. Res. 2010, 3, 2036-2038.

[56] Ângelo, M. L. Análise Químico-Farmacêutica de Rosuvastatina Cálcica Comprimido e Cápsula. Ph.D. thesis, Federal University of Alfenas: Alfenas, Minas Gerais, Brazil, 2016.

[57] Sevda, R. R; Ravetkar, A. S.; Shirote, P. J. UV Spectrophotometric Estimation of Rosuvastatin Calcium and Fenofibrate in Bulk Drug and Dosage Form Using Simultaneous Equation Method. Int. J. ChemTech Res. 2011, 3, 629-635.

[58] El-Bagary, R. I.; El-Kady, E. F.; Kadry, A. M. Spectrofluorometric Determination of Certain Antihyperlipidemic Agents in Bulk and Pharmaceutical Preparations. Spectroscopy 2012, 27, 83-92.

[59] Patel, B.; Jadav, A.; Solanki, H.; Parmar, S.; Parmar, V.; Captain, A. Development and Validation of Derivative Spectroscopic Method for the Simultaneous Estimation of Rosuvastatin Calcium and Fenofibrate in Tablet. Int. J. Pharma Res. Rev. 2013, 2, 1-6.

[60] Ambole, S. R.; Shirote, P. J.; Kondawar, M. S. Simultaneous Estimation for Rosuvastatin Calcium and Aspirin from Capsule Dosage Forms by First Order Derivative Spectroscopic Method. Int. J. ChemTech Res. 2012, 4, 966-970.

[61] Karunakaran, A.; Subhash, V.; Chinthala, R.; Muthuvijayan, J. Simultaneous Estimation of Rosuvastatin Calcium and Fenofibrate in Bulk and in Tablet Dosage Form by UV-Spectrophotometry and RP-HPLC. S. J. Pharm. Sci. 2011, 4 (1), 58-63.

[62] Sharma, S.; Bhandari, P. Simultaneous Estimation of Rosuvastatin Calcium and Fenofibrate in Bulk and in Tablet Dosage Form by UV-Spectrophotometry and RP-HPLC. J. Pharm. Res. 2012, 5, 2311-2314.

[63] Afroz, A.; Haque, T.; Talukder, M. U; Islam, S. M. A. Spectrophotometric Estimation of Rosuvastatin Calcium and Glimepiride in Tablet Dosage Form. Asian J. Pharm. Anal. 2011, 1, 74-78.

[64] Parmar, V.; Solanki, H.; Prajapati, L. Derivative Spectrophotometric Determination of Rosuvastatin Calcium and Fenofibrate in Tablet Dosage Form. Inventi Rapid: Pharm. Anal. Qual. Assur. 2013, 2, 1-5.

[65] Dudhipala, N.; Veerabrahma, K. Improved Anti-Hyperlipidemic Activity of Rosuvastatin Calcium Via Lipid Nanoparticles: Pharmacokinetic and Pharmacodynamic Evaluation. Eur. J. Pharm. Biopharm. 2017, 110, 47-57.
[66] Nazir, S.; Iqbal, Z.; Nasir, F. Impact of Menopause on Pharmacokinetics of Rosuvastatin Compared with Premenopausal Women. Eur. J. Drug Metab. Pharmacokinet. 2016, 41, 505-509.

[67] Beludari, M. H.; Prakash, K. V.; Mohan, G. K. RP-HPLC Method for Simultaneous Estimation of Rosuvastatin and Ezetimibe from Their Combination Tablet Dosage Form. Int. J. Chem. Anal. Sci. 2013, 4, 205-209.

[68] Balakumar, K.; Raghavana, C. V.; Selvana, N. T.; Prasadb, R. H.; Abdua, S. Self Nanoemulsifying Drug Delivery System (SNEDDS) of Rosuvastatin Calcium: Design, Formulation, Bioavailability and Pharmacokinetic Evaluation. Colloids Surf. B 2013, 112, 337-343.

[69] Kumar, T. R.; Shitut, N. R.; Kumar, P. K.; Vinu, M. C. A.; Venkata V. P.; Kumar, R. M.; Nuggehally, R. S. Determination of Rosuvastatin in Rat Plasma by HPLC: Validation and its Application to Pharmacokinetic Studies. Biomed. Chromatogr. 2006, 20, 881-887.

[70] Caglar, S.; Toker, S. Determination of Rosuvastatin at Picogram Level in Serum by Fluorimetric Derivatization with 9-Anthryldiazomethane Using HPLC. J. Chromatogr. Sci. 2013, 51, 53-58.

[71] Eswarudu, M. M.; Mounica, P.; Venkatesh, D.; Nagalakshmi, B. Method Development and Validation for Simultaneous Estimation of Rosuvastatin Calcium and Ezetimibe in Pharmaceutical Dosage Form by RP-HPLC. Int. Res. J. Pharm. App. Sci. 2012, 2, 24-36.

[72] Trivedi, H. K.; Patel, M. C. Development and Validation of a Stability-Indicating RP-UPLC Method for Determination of Rosuvastatin and Related Substances in Pharmaceutical Dosage Form. Sci. Pharm. 2012, 80, 393-406.

[73] Rao, A. L.; Suneetha, D. Development and Validation of RP-HPLC Method for the Estimation of Rosuvastatin in Bulk and Pharmaceutical Dosage Form. Int. J. Chem. Sci. 2010, 8, 1308-1314.

[74] Haq, N.; Shakeel, F.; Alanazi, F.; Alshora, D. H.; Ibrahim, M. A Development and Validation of a Green RP-HPLC Method for the Analysis of Rosuvastatin: A Step Towards Making Liquid Chromatography Environmentally Benign. Green Process. Synth. 2017, 6, $1-10$.

[75] Mostafa, N. M.; Badawey, A. M.; Lamie, N. T.; El-Aleem, A. E. B. E Selective Chromatographic Methods for the Determination of Rosuvastatin Calcium in the Presence of its Acid Degradation Products. J. Liq. Chromatogr. Relat. Technol. 2014, 37, 2182-2196.

[76] Kaila, H. O.; Ambasana, M. A.; Thakkar, R. S.; Saravaia, H. T.; Shah, A. K. A New Improved RP-HPLC Method for Assay of Rosuvastatin Calcium in Tablets. Indian J. Pharm. Sci. 2010, 72, 592-598.

[77] Hassouna, M. K. M.; Abdel-Mageed, A. I.; Salem, H. O. Indirect Oxygen Flask-Atomic Absorption Spectrometric Determination of Rosuvastatin Calcium. Biomed. J. Sci. Tech. Res. 2017, 1, 1-6.

[78] Janardhanan, V. S.; Manavalan, R.; Valliappan, K. Chemometric Technique for the Optimization of Chromatographic System: Simultaneous HPLC Determination of Rosuvastatin, Telmisartan, Ezetimibe and Atorvastatin Used in Combined Cardiovascular Therapy. Arab. J. Chem. 2016, 9, S1378-S1387.

[79] Kishore, C. R. P.; Krishna Mohan, G. V. Structural Identification and Estimation of Rosuvastatin Calcium Related Impurities in Rosuvastatin Calcium Tablet Dosage Form. Anal. Chem. Res. 2017, $12,17-27$.

[80] Shah, Y.; Iqbal, Z.; Ahmad, L.; Khan, A.; Khan, M. I.; Nazir, S.; Nasir, F. Simultaneous Determination of Rosuvastatin and Atorvastatin in Human Serum Using RP-HPLC/UV Detection: Method Development, Validation and Optimization of Various Experimental Parameters. J. Chromatogr. B 2011, 879, 557-563.

[81] Vittal, S.; Shitut, N. R.; Kumar, T. R.; Vinu, M. C.; Mullangi, R.; Srinivas, N. R. Simultaneous Quantitation of Rosuvastatin and Gemfibrozil in Human Plasma by High-Performance Liquid Chromatography and Its Application to a Pharmacokinetic Study. Biomed. Chromatogr. 2006, 20, 1252-1259.

[82] Gomes, F. P.; García, P. L.; Alves, J. M. P.; Singh, A. K.; KedorHackmann, E. R. M.; Santoro, M. I. R. M. Development and Validation of Stability-Indicating HPLC Methods for Quantitative Determination of Pravastatin, Fluvastatin, Atorvastatin, and Rosuvastatin in Pharmaceuticals. Anal. Lett. 2009, 42, 1784-1804.

[83] Arayne, M. S.; Sultana, M.; Tabassum, A.; Ali, S. N.; Naveed, S. Simultaneous LC Determination of Rosuvastatin, Lisinopril 
Captopril, and Enalapril in API, Pharmaceutical Dosage Formulations, and Human Serum. Med. Chem. Res. 2012, 21, 4542-4548.

[84] Sri, D. S.; Kumar, T. H.; Rao, V. P. K.; Rao, Y. S. Validated RPHPLC Method for Simultaneous Determination of Rosuvastatin Calcium and Ezetimibe in Pharmaceutical Dosage Form. Int. J. Pharm. Pharm. Sci. 2015, 7, 209-213.

[85] Sultana, N.; Arayne, M. S.; Shah, S. N.; Shafib, N.; Naveed, S. Simultaneous Determination of Prazosin, Atorvastatin, Rosuvastatin and Simvastatin in API, Dosage Formulations and Human Serum by RP-HPLC. J. Chin. Chem. Soc. 2010, 57, 1286-1292.

[86] Sultana, N.; Arayne, M. S.; Shahzad, W. Simultaneous Determination of Ceftriaxone Sodium and Statin Drugs in Pharmaceutical Formulations and Human Serum by RP-HPLC. J. Chil. Chem. Soc. 2010, 55, 193-198.

[87] Arayne, M. S.; Sultana, N.; Mirza, A. Z.; Shamshad, H. High-Performance Liquid Chromatographic Analysis of Pioglitazone, Gliquidone, Rosuvastatin and Simvastatin in Formulations and Human Serum. Chin. J. Chem. 2010, 28, 1998-2002.

[88] Gajjar, A. K.; Shah, V. D. Development and Validation of a Stability-Indicating Reversed-Phase HPLC Method for Simultaneous Estimation of Rosuvastatin and Ezetimibe from Their Combination Dosage Forms. Eurasian J. Anal. Chem. 2010, 5, 280-298.

[89] Sultana, N.; Arayne, M. S.; Ali, S. N. An Ultra-Sensitive LC method for Simultaneous Determination of Rosuvastatin, Alprazolam and Diclofenac Sodium in API, Pharmaceutical Formulations and Human Serum by Programming the Detector. J. Anal. Bioanal. Tech. 2012, 3, 1-6.

[90] Ashfaq, M.; Ahmad, H.; Khan, I. U.; Mustafalc, G. Determination of Rosuvastatin and Ezetimibe in Human Plasma. J. Chil. Chem. Soc. 2013, 58, 2177-2181.

[91] Tabassum, A.; Arayne, M. S.; Sultana, N. Quantitation and Monitoring of Gemifloxacin and Rosuvastatin by Liquid Chromatography with UV-Detection. Int. J. Adv. Res. 2014, 2, 842-851

[92] Pasha, K.; Muzeeb, S.; Basha, S. J. S.; Shashikumar, D.; Mullangi, R.; Srinivas, N. R. Analysis of Five HMG-CoA Reductase InhibitorsAtorvastatin, Lovastatin, Pravastatin, Rosuvastatin and Simvastatin: Pharmacological, Pharmacokinetic and Analytical Overview and Development of a New Method for Use in Pharmaceutical Formulations Analysis and In Vitro Metabolism Studies. Biomed. Chromatogr. 2006, 20, 282-293.

[93] Shamshad, H.; Sultana, N.; Arayne, M. S. Simultaneous Determination of Cetirizine, Atorvastatin, Simvastatin, Rosuvastatin or Pravastatin in Formulations and Human Serum by RP-HPLC. J. Anal. Chem. Lett. 2015, 5, 109-116.

[94] Üstün, Z.; Talay, A.; Demiralay, E. C. Optimization of RPLC Conditions for Quantitative Analysis of Atorvastatin and Rosuvastatin in Pharmaceutical Dosage Form. SDU J. Sci. 2016, 11, 72-81.

[95] Al- Akkam, E. J.; Arasool, A. A. A.; Badwan, A. A; Al-Jbour, N. D; Qinna, N. A. Development and Validation of a Sensitive and Accurate Method for Determination of Atorvastatin and Rosuvastatin in Rat Plasma by Reversed Phase High Performance Liquid Chromatography with UV Detection. Int. J. Pharm. Pharm. Sci. 2013, 5, 211-219.

[96] Nasir, F.; Iqbala, Z.; Khana, A.; Ahmada, L.; Shaha, Y.; Khana, A. Z.; Khana, J. A.; Khanb, S. Simultaneous Determination of Timolol Maleate, Rosuvastatin Calcium and Diclofenac Sodium in Pharmaceuticals and Physiological Fluids Using HPLC-UV. J. Chromatogr. B 2011, 879, 3434-3443.

[97] Ashfaq, M.; Akhtar, T.; Mustafa, G.; Danish, M.; Razzaq, S. N.; Nazar, M. F. Simultaneous Estimation of Rosuvastatin and Amlodipine in Pharmaceutical Formulations Using Stability Indicating HPLC Method. Braz. J. Pharm. Sci. 2014, 50, 629-638.

[98] Tajane, D.; Raurale, A. M.; Bharande, P. D.; Mali, A. N.; Gadkari, A. V.; Bhosale, V. R. Development and Validation of a RP-HPLCPDA Method for Simultaneous Determination of Rosuvastatin Calcium and Amlodipine Besylate in Pharmaceutical Dosage Form. J. Chem. Pharm. Res. 2012, 4, 2789-2794.

[99] Gaikwad, S.; Kawale, L. A.; Ahire, K.; Yadav, S.; Bodile, S. Development and Validation of Stability Indicating RP-HPLC Method for Simultaneous Estimation of Rosuvastatin Calcium and Fenofibrate in Bulk and Pharmaceutical Dosage Form. Indo Am. J. Pharm. Res. 2016, 6, 5521-5530.

[100] Khivasara, A.; Kawale, L. A.; Shirode, L.; Badhe, N.; Ahire, P.; Lale, S. Development and Validation of Stability Indicating RP-HPLC Method for Simultaneous Estimation of Rosuvastatin Calcium and Aspirin in Bulk and Pharmaceutical Dosage Form. Indo Am. J. Pharm. Res. 2016, 6, 4417-4426.

[101] Sumalatha, M.; Pavani, K. H. Analytical Method Development and Validation for the Simultaneous Estimation of Rosuvastatin and Fenofibate in Tablet Dosage Form by Reverse Phase High Performance Liquid Chromatography. Indian J. Res. Pharm. Biotechnol. 2013, 1, 850-856.

[102] Murthy, T. G. K.; Geethanjali, J. Development of a Validated RPHPLC Method for Simultaneous Estimation of Metformin Hydrochloride and Rosuvastatin Calcium in Bulk and In-House Formulation. J. Chromatogr. Sep. Tech. 2014, 5, 1-7.

[103] Mukthinuthalapati, M. A.; Bukkapatnam, V.; Bandaru, S. P. K. Stability Indicating Liquid Chromatographic Method for the Simultaneous Determination of Rosuvastatin and Ezetimibe in Pharmaceutical Formulations. Adv. Pharm. Bull. 2014, 4, 405-411.

[104] Savita, M. N.; Promod, H. S.; Chandrashekhar, L. B.; Pramod, L. I. Development and Validation of RP-HPLC Method for the Estimation of Rosuvastatin Calcium and Niacin in Combined Tablet Dosage Form. Int. J. Pharma Res. Rev. 2015, 4, 44-50.

[105] Sagar, G. V.; Parameswari, S. A.; Chetty, C. M.; Kumar, A. V. S. Development and Validation of RP-HPLC Method for Simultaneous Determination of Rosuvastatin Calcium and Clopidogrel in Capsule Dosage Form. J. Pharm. Res. 2012, 5, 4881-4883.

[106] Devika, G. S.; Sudhakar, M.; Venkateshwara, R. J. A New Improved RP-HPLC Method for Simultaneous Estimation of Rosuvastatin Calcium and Fenofibrate in Tablets. Int. J. Pharm. Pharm. Sci. 2011, 3, 311-315.

[107] Reddy, G. V. R.; Reddy, B. V.; Haque, S. W.; Gautam, H. D.; Kumar, P. Development and Validation of a Stability-Indicating UPLC Method for Rosuvastatin and Its Related Impurities in Pharmaceutical Dosage Forms. Quim. Nova 2011, 34, 250-255.

[108] Lan, K.; Jiang, X.; Li, Y.; Wang, L.; Zhou, J.; Jiang, Q.; Ye, L. Quantitative Determination of Rosuvastatin in Human Plasma by Ion Pair Liquid-Liquid Extraction Using Liquid Chromatography with Electrospray Ionization Tandem Mass Spectrometry. J. Pharm. Biomed. Anal. 2007, 44, 540-546.

[109] Gao, J.; Zhonga, D.; Duana, X.; Chena, X. Liquid Chromatography/ Negative Ion Electrospray Tandem Mass Spectrometry Method for the Quantification of Rosuvastatin in Human Plasma: Application to a Pharmacokinetic Study. J. Chromatogr. B 2007, 856, 35-40.

[110] Xu, D.; Ruan, Z.; Zhou, Q.; Yuan, H.; Jiang, B. Quantitative Determination of Rosuvastatin in Human Plasma by Liquid Chromatography with Electrospray Ionization Tandem Mass Spectrometry. Rapid Commun. Mass Spectrom. 2006, 20, 2369-2375.

[111] Kallem, R. R.; Karthik, A.; Chakradhar, L.; Mullangi R.; Srinivas, N. R. Development and Validation of a Highly Sensitive and Robust LC-MS/ MS with Electrospray Ionization Method for Quantification of Rosuvastatin in Small Volume Human Plasma Samples and Its Application to a Clinical Study. Arzneim. Forsch. Drug Res. 2007, 57, 705-711.

[112] Zhang, D.; Zhang, J.; Liu, X.; Wei, C.; Zhang, R.; Song, H.; Yao, H.; Yuan, G.; Wang, B.; Guo, R. Validated LC-MS/MS Method for the Determination of Rosuvastatin in Human Plasma: Application to a Bioequivalence Study in Chinese Volunteers. Pharmacol. Pharm. 2011, 2, 341-346.

[113] Hull, C.K.; Penman, A. D.; Smith, C. K.; Martin, P. D. Quantification of Rosuvastatin in Human Plasma by Automated Solid Phase Extraction Using Tandem Mass Spectrometric Detection. J. Chromatogr. B 2002, 772, 219-228.

[114] Oudhoff, K. A.; Sangster, T.; Thomas, E.; Wilson, I. D. Application of Microbore HPLC in Combination with Tandem MS for the Quantification of Rosuvastatin in Human Plasma. J. Chromatogr. B 2006, 832, 191-196.

[115] Hussain, S.; Patel, H.; Tan, A. Automated Liquid-Liquid Extraction Method for High-Throughput Analysis of Rosuvastatin in Human EDTA K2 Plasma by LC-MS/MS. Bioanalysis 2009, 1, 529-535. 
[116] Siddartha, B.; Babu, I. S. Estimation and Validation for Determination of Rosuvastatin in Human Plasma by LC/MS/MS Method. J. Global Trends Pharm. Sci. 2014, 5, 1979-1988.

[117] Singh, S. S.; Sharma, H.; Patel, H.; Jain, M.; Shah, H.; Gupta, S.; Thakkar, P.; Patel, N.; Singh, S. P.; Lohray, B. B. Estimation of Rosuvastatin in Human Plasma by HPLC Tandem Mass Spectroscopic Method and Its Application to Bioequivalence Study. J. Braz. Chem. Soc. 2005, 16, 944-950.

[118] Narapusetti, A.; Bethanabhatla, S. S.; Sockalingam, A.; Repaka, N.; Saritha, V. Simultaneous Determination of Rosuvastatin and Amlodipine in Human Plasma Using Tandem Mass Spectrometry: Application to Disposition Kinetics. J. Adv. Res. 2015, 6, 931-940.

[119] Trivedi, R. K.; Kallem, R. R.; Mullangi, R.; Srinivas, N. R. Simultaneous Determination of Rosuvastatin and Fenofibric Acid in Human Plasma by LC-MS/MS with Electrospray Ionization: Assay Development, Validation and Application to a Clinical Study. J. Pharm. Biomed. Anal. 2005, 39, 661-669.

[120] Macwan, J. S.; Ionita, I. A.; Akhlaghi, F. A Simple Assay for the Simultaneous Determination of Rosuvastatin Acid, Rosuvastatin5S-Lactone, and N-Desmethyl Rosuvastatin in Human Plasma Using Liquid Chromatography-Tandem Mass Spectrometry (LCMS/MS). Anal. Bioanal. Chem. 2012, 402, 1217-1227.

[121] Kosek, V.; Stránská, M.; Fenclová, M.; Ruml, T.; Vítek, L.; Hajšlová, J. High Resolution Mass Spectrometry Based Method Applicable for a Wide Range of 3-hyroxy-3-methyl-glutaryl-coenzyme A Reductase Inhibitors in Blood Serum Including Intermediates and Products of the Cholesterol Biosynthetic Pathway. J. Chromatogr. A 2017, 17, 86-94.

[122] Varghese, S. J.; Ravi, T. K. Development and Validation of a Liquid Chromatography/Mass Spectrometry Method for the Simultaneous Quantitation of Rosuvastatin and Ezetimibe in Human Plasma. J. AOAC Int. 2013, 96, 307-311.

[123] Shah, Y.; Iqbal, Z.; Ahmad, L.; Nazir, S.; Watson, D. G.; Khuda, F.; Khana, A.; Khan, M. I.; Khan, A.; Nasir, F. Determination of Rosuvastatin and Its Metabolite N-desmethyl Rosuvastatin in Human Plasma by Liquid Chromatography-High Resolution Mass Spectrometry: Method Development, Validation and Application to Pharmacokinetic Study. J. Liq. Chromatogr. Relat. Technol. 2015, 38, 863-873.

[124] Kumar, P. P.; Murthy T. E.; Rao, M. V. B. Development, Validation of Liquid Chromatography-Tandem Mass Spectrometry Method for Simultaneous Determination of Rosuvastatin and Metformin in Human Plasma and Its Application to a Pharmacokinetic Study. J. Adv. Pharm. Technol. Res. 2015, 6, 118-124.

[125] Bai, X.; Wang, X.-.P.; He, G.-.D.; Zhang, B.; Huang, M.; Li, J.-.L.; Zhong, S.-.L. Simultaneous Determination of Rosuvastatin, Rosuvastatin-5 Slactone, and n-desmethyl Rosuvastatin in Human Plasma by UPLCMS/MS and Its Application to Clinical Study. Drug Res. 2017, 67, 1-7. DOI: 10.1055/s-0043-123576.

[126] Gumustas, M.; Kurbanoglu, S.; Uslu, B.; Ozkan, S. A. UPLC Versus HPLC on Drug Analysis: Advantageous, Applications and Their Validation Parameters. Chromatographia 2013, 76, 1365-1427.

[127] Wani, T. A.; Darwish, I. A. Development and Validation of UltraPerformance Liquid Chromatography-Tandem Mass Spectrometry Method for Determination of Cediranib in Human Plasma. Main Group Chem. 2015, 14, 349-357.

[128] Wani, T. A.; Khalil, N. Y.; Darwish, I.; Iqbal, M.; Bakheit, A. H. Highly Sensitive and Simple Validated Ultra-Performance Liquid Chromatography/Tandem Mass Spectrometry Method for the Determination of Cinacalcet in Human Plasma. Cur. Pharm. Anal. 2014, 10, 51-57.

[129] Martin, P. D.; Warwick, M. J.; Dane, A. L.; Hill, S. J.; Giles, P. B.; Phillips, P. J.; Lenz, E. Metabolism, Excretion, and Pharmacokinetics of Rosuvastatin in Healthy Adult Male Volunteers. Clin. Ther. 2003, 25, 2822-2835.
[130] Silva, T. A.; Zaninb, H.; Vicentinia, F. C.; Coratc, E. J.; Orlando, F. -F. Electrochemical Determination of Rosuvastatin Calcium in Pharmaceutical and Human Body Fluid Samples Using a Composite of Vertically Aligned Carbon Nanotubes and Graphene Oxide as the Electrode Material. Sens. Actuators B 2015, 218, 51-59.

[131] Purkar, A. J.; Balap, A. R.; Sathiyanarayanan, L.; Mahadik, K. R. Development and Validation of HPTLC Method for Simultaneous Determination of Rosuvastatin Calcium and Aspirin in Its Pure and Pharmaceutical Dosage Form. Int. J. Pharm. Pharm. Sci. 2014, 6 704-706.

[132] Suslu, I.; Celebier, M.; Altınoz, S. Determination of Rosuvastatin in Pharmaceutical Formulations by Capillary Zone Electrophoresis. Chromatographia 2007, 66, 65-72.

[133] Altınöz, S.; Uyara, B. Electrochemical Behaviour and Voltammetric Determination of Rosuvastatin Calcium in Pharmaceutical Preparations Using a Square-Wave Voltammetric Method. Anal. Methods 2013, 5, 5709-5716.

[134] Sane, R.; Kamat, S.; Menon, S.; Inamdar, S.; Mote, M. Determination of Rosuvastatin Calcium in Its Bulk Drug and Pharmaceutical Preparations by High-Performance Thin-Layer Chromatography. J. Planar Chromatogr. - Mod. TLC 2005, 18, 194-198.

[135] Darwish, I. A.; Al-Obaid, A. M.; A Al-Malaq, H. A. Generation of Polyclonal Antibody with High Avidity to Rosuvastatin and Its Use in Development of Highly Sensitive ELISA for Determination of Rosuvastatin in Plasma. Chem. Cent. J. 2011, 5, 1-8.

[136] El-Kommos, M. E.; Mohamed, N. A.; Ali, H. R. H.; Hakiem, A. F. A. Micellar Electrokinetic Chromatographic Determination of Rosuvastatin in Rabbit Plasma and Evaluation of Its Pharmacokinetics and Interaction with Niacin. Biomed. Chromatogr. 2014, 28, 18281838 .

[137] Alzoman, N. Z.; Sultan, M. A.; Maher, H. M.; Alshehri, M. M.; Wani, T. A.; Darwish, I. A. Analytical Study for the Charge-Transfer Complexes of Rosuvastatin Calcium with $\pi$-acceptors. Molecules 2013, 18, 7711-7725.

[138] Wani, T. A.; Darwish, I. A.; Khalil, N. Y. Novel Microwell-Based Spectrophotometric Assay for the Determination of Rosuvastatin Calcium in Its Pharmaceutical Formulations. Curr. Pharm. Anal. 2013, 9, 54-60.

[139] Wani, T. A.; Khalil, N. Y.; Abdel-Rahman, H. M.; Darwish, I. A. Novel Microwell-Based Spectrophotometric Assay for Determination of Atorvastatin Calcium in Its Pharmaceutical Formulations. Chem. Cent. J. 2011, 5, 57.

[140] Wani, T. A.; Ahmad, A.; Zargar, S.; Khalil, N. Y.; Darwish, I. A. Use of Response Surface Methodology for Development of New Microwell-Based Spectrophotometric Method for Determination of Atorvastatin Calcium in Tablets. Chem. Cent. J. 2012, 6, 134.

[141] Wani, T.A.; Zargar, S.; Wakil, S. M.; Darwish, I. A. New Analytical Application of Antibody-Based Biosensor in Estimation of Thyroid-Stimulating Hormone in Serum. Bioanalysis 2016, 8, 625-632.

[142] Wani, T. A.; Zargar, S.; Majid, S.; Darwish, I. A. Analytical Application of Flow Immunosensor in Detection of Thyroxine and Triiodothyronine in Serum. Assay Drug Dev. Technol. 2016, 14, 535-542.

[143] Darwish, I. A.; Wani, T. A.; Alanazi, A. M.; Hamidaddin, M. A.; Zargar, S. Kinetic-Exclusion Analysis-Based Immunosensors Versus Enzyme-Linked Immunosorbent Assays for Measurement of Cancer Markers in Biological Specimens. Talanta 2013, $111,13-19$.

[144] Puszkiel, A.; Nóe, G.; Boudou-Rouquette, P.; Cossec, C. L.; Arrondeau, J.; Giraud, J. S.; Thomas-Schoemann, A.; Alexandre, J.; Vidal, M.; Goldwasser, F. et al. Development and Validation of an ELISA Method for the Quantification of Nivolumab in Plasma from NonSmall-Cell Lung Cancer Patients. J. Pharm. Biomed. Anal. 2017, $139,30-36$. 